ARTICLE

DOI: $10.1038 / \mathrm{s} 41467-017-00649-7$

\title{
A rechargeable iodine-carbon battery that exploits ion intercalation and iodine redox chemistry
}

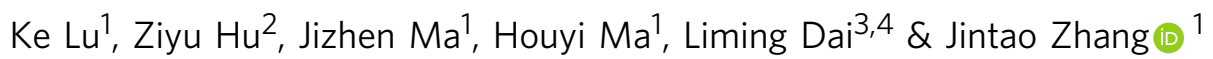

Graphitic carbons have been used as conductive supports for developing rechargeable batteries. However, the classic ion intercalation in graphitic carbon has yet to be coupled with extrinsic redox reactions to develop rechargeable batteries. Herein, we demonstrate the preparation of a free-standing, flexible nitrogen and phosphorus co-doped hierarchically porous graphitic carbon for iodine loading by pyrolysis of polyaniline coated cellulose wiper. We find that heteroatoms could provide additional defect sites for encapsulating iodine while the porous carbon skeleton facilitates redox reactions of iodine and ion intercalation. The combination of ion intercalation with redox reactions of iodine allows for developing rechargeable iodine-carbon batteries free from the unsafe lithium/sodium metals, and hence eliminates the long-standing safety issue. The unique architecture of the hierarchically porous graphitic carbon with heteroatom doping not only provides suitable spaces for both iodine encapsulation and cation intercalation but also generates efficient electronic and ionic transport pathways, thus leading to enhanced performance.

\footnotetext{
${ }^{1}$ Key Laboratory for Colloid and Interface Chemistry, Ministry of Education, School of Chemistry and Chemical Engineering, Shandong University, Jinan 250100, China. ${ }^{2}$ College of Science, Beijing University of Chemical Technology (BUCT), Beijing 100029, China. ${ }^{3}$ BUCT-CWRU International Joint Laboratory, College of Energy, Beijing University of Chemical Technology, Beijing 100029, China. ${ }^{4}$ Center of Advanced Science and Engineering for Carbon (Case4carbon), Department of Macromolecular Science and Engineering, Case Western Reserve University, 10900 Euclid Avenue, Cleveland, OH 44106, USA. Correspondence and requests for materials should be addressed to L.D. (email: liming.dai@case.edu) or to J.Z. (email: jtzhang@sdu.edu.cn)
} 


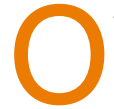
ver the past decades, Li-ion batteries (LIBs), consisting of a lithium-containing cathode and a graphite anode, have demonstrated great success for energy storage via the classic lithium intercalation process ${ }^{1-4}$. However, the specific capacity of LIBs is limited by the cathode, which is still far below the theoretical capacity of graphite $\left(372 \mathrm{mAh} \mathrm{g}^{-1}\right)$ and has to be significantly improved in order to meet the ever increasing energy storage demand $d^{5-8}$. Along with intensive research on the exploitation of advanced cathode materials of novel chemical and/or physical structures ${ }^{9-11}$, many other rechargeable batteries, such as Na-ion battery ${ }^{12}, 13, \mathrm{Li}-\mathrm{S}$ battery ${ }^{4}$, and Li-/Na-iodine battery $^{14-16}$ have been devised. Recent publications reported rechargeable Li-iodine batteries with a high theoretical energy density/discharge capacity of $612 \mathrm{Wh} \mathrm{kg}^{-1} / 211 \mathrm{mAh} \mathrm{g}^{-1}$ based on the highly reversible electrochemical redox reaction between the lithium anode and iodine cathode $\left(2 \mathrm{Li}+\mathrm{I}_{2} \leftrightarrow 2 \mathrm{LiI}\right)^{14}, 15$. Although the abundance of iodine resource in ocean ${ }^{14-18}$ makes the rechargeable Li-iodine batteries particularly interesting as low-cost, but efficient, alternatives to LIBs, inexpensive and highly conducting iodine-based cathodes with a stable and high iodine loading still need to be developed. So far, a few carbon hosts, including porous carbons, have been developed for Li-iodine batteries $^{4}, 15,18,19$. However, the use of heteroatom-doped/ functionalized carbon supports to enhance the iodine loading, and hence the battery performance, has been rarely discussed. As for LIBs, the practical application of Li-iodine batteries is also still hindered by the safety risk intrinsically associated with the metallic lithium electrode due to the lithium dendrite formation and its high activity with moisture ${ }^{1,3}$.

Carbon-based electrodes have been widely used for energy storage/conversion with their performance being strongly dependent on the composition and microstructure of the carbon materials $^{19-23}$. In this context, heteroatom (e.g., B, N, P, and S) doping of graphitic carbons has been proven to significantly improve the electrocatalytic activities for metal-air batteries and enhance the capacity and cycling stability of Li-S batteries ${ }^{13,24-26}$. Specifically, three-dimensional (3D) conductive porous carbon networks, when used as the anode, have been demonstrated to improve the energy storage performance of lithium/sodium ion batteries by enhancing the ion intercalation ${ }^{27}$. On the other hand, pre-lithiation/sodiation of a carbon anode provides a lithium/ sodium reservoir to tune the cell potential ${ }^{28,29}$. However, it still remains a challenge to incorporate the ion intercalation with redox reactions, for example associated with iodine, to enhance the performance of rechargeable full batteries. Additionally, kinetic balance between anode and cathode still remains elusive. Therefore, it is highly desirable to rationally design electrode materials intercalated with redox active moieties ${ }^{28-32}$ to overcome the discrepancy between cathodic and anodic kinetics, in particular, and to enhance the battery performance, in general.

Herein, we report a free-standing hierarchically porous carbon matrix co-doped with nitrogen and phosphorus (HPCM-NP) prepared by pyrolysis of polyaniline coated cellulose wiper in the presence of phytic acid as the phosphorous source. The resultant free-standing conductive HPCM-NP renders the facile preparation of iodine-containing cathodes (i.e., iodine-carbon cathode) free from current collector, conductive additive, or any additional binder. The highly porous structure, coupled with the heteroatom co-doping, ensures a remarkably high iodine loading up to $125 \mathrm{wt} \%$. Our results reveal that both the chemical and physical structures of HPCM-NP play important roles in regulating the iodine adsorption and subsequent electrochemical performance. Rechargeable $\mathrm{Li}$-iodine and $\mathrm{Na}$-iodine batteries based on the iodine-containing HPCM-NP cathodes exhibit a high discharge capacity of 386 and $253 \mathrm{mAh} \mathrm{g}^{-1}$, respectively, along with a good rate-performance and good cycle stability with $84.5 \%$ capacity retention after 2000 cycles for the Li-iodine battery and $85.0 \%$ capacity retention after 500 cycles for the Na-iodine battery. To avoid the use of the unsafe metallic $\mathrm{Li}$ and $\mathrm{Na}$ anode, we further constructs rechargeable batteries from the iodine-carbon cathode ( $\mathrm{I}_{2}$-HPCM-NP) and carbon cloth anode (HPCM-NP) with an electrolyte containing lithium (sodium) ions (e.g., LiTFSI, $\mathrm{NaClO}_{4}$ ), which exhibits a reversible capacity of 217 (182) $\mathrm{mAh} \mathrm{g}^{-1}$, high energy density of 166 (153) $\mathrm{Wh} \mathrm{kg}^{-1}$ and good cycle performance with a $76.7 \%$ capacity retention after 500 cycles $(69.8 \%$ @300 cycles) at a current density of $500 \mathrm{~mA} \mathrm{~g}^{-1}$. Our kinetics and mechanistic studies reveal that proper encapsulation of iodine into the HPCM-NP electrodes with a hierarchically porous structure and a controllable heteroatom doping level could efficiently enhance the Li-/Na-ion intercalation and electrolyte diffusion whilst restoring a kinetic balance between the anode and cathode electrodes, leading to the good battery performance.

\section{Results}

Structure characterization of iodine-carbon composite. Figure 1a schematically illustrates the preparation process for HPCM-NP through an interfacial polymerization of aniline on a cellulose wiper in the presence of phytic acid, followed by carbonization. The oxidative polymerization of aniline monomers in the presence of phytic acid led to the formation of porous polyaniline (PANi) along individual fibers in the cellulose wiper. The subsequent pyrolysis of PANi coated cellulose wiper at an elevated temperature resulted in the formation of HPCM-NP. The optimized condition for the formation of HPCM-NP was determined by adjusing the amount of aniline monomers (Supplementary Figs. 1, 2 and Supplementary Note 1). Then, iodine can be facily loaded into the porous carbon matrix via surface adsorption from an iodine saturated aqueous solution (see Methods for detailed procedure). Large-scale of free-standing and highly flexible HPCM-NP scaffold can be prepared as its size is mainly determined by the size of the starting cellulose wiper (Fig. 1b). Scanning electron microscopy (SEM) and transmission electron microscopy (TEM) images show that the flexible HPCM$\mathrm{NP}$ knits with flexible ligaments (Fig. 1c), and the individual carbon fibers are coverved uniformly with the hierarchical porous carbon network (Figs. 1d, e). The high-resolution TEM image further reveals that the shells of these interconnected fibers contain a myriad of micropores (Fig. 1f, $c f$. Figs. 2b, c). For comparison, carbonized pure cellulose wiper and PANi aerogel were also prepared at the same elevated temperature (Supplementary Figs. 3, 4). To load iodine, these as-prepared carbon scaffolds were immersed into the iodine saturated aqueous solution at room temperature (Supplementary Fig. 5). The hierarchically porous structure with a large surface area facilitated the penetration of the iodine solution into the inside of carbon matrix, possibly by an energtic capilary action ${ }^{15,19}, 33$, and the adsorption of iodine species throughtout the entire carbon matrix homogenously rather than accumulate on the outmost surface only ${ }^{4}, 34$. This was confirmed by the element mapping analysis along the whole carbon fiber (Fig. 1g) and the EDX spectrum for the bulk sample (Supplementary Fig. 6). The same procedure was used to load iodine into other carbon materials, including the pure porous carbon cloth (CC) (Supplementary Fig. 5), N and P co-doped porous carbon foam (NPCF) (Supplementary Fig. 4) and activated carbon (AC) (Supplementary Fig. 7 and Supplementary Note 2). It was noticed that the co-doping of HPMC-NP with $\mathrm{N}$ and $\mathrm{P}$ could enhance the uploading of iodine species ( $c f$. Fig. $2 a)^{14,34}$. The hierarchically porous frameworks of HPMCNP can act as effective physical barriers for preventing the dissolution of the adsorbed iodine (Supplementary Fig. 8), but efficient pathways for electron transfer via the highly conductive 3D 

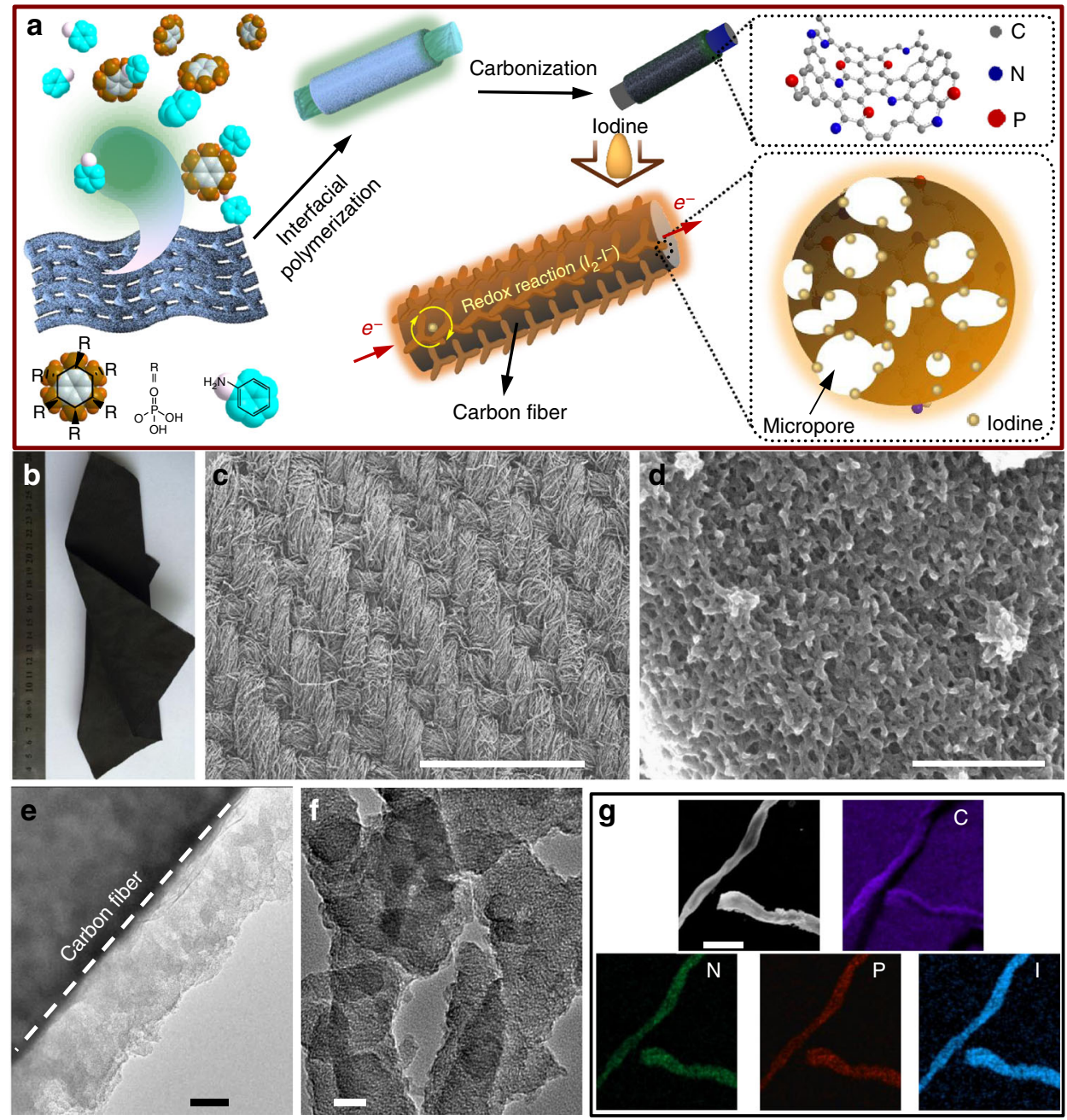

Fig. 1 Preparation of HPMC-NP and the loading iodine. a Interfacial deposition of PANi on the cellulose wiper via an oxidative polymerization in the presence of phytic acid and the subsequent carbonization in $\mathrm{N}_{2}$ atmosphere. Then, iodine is escasulated into the as-prepared HPMC-NP from the iodinesaturated solution. b The digital photograph, c, d SEM images (Scale Bar, $1 \mathrm{~mm}$ and $500 \mathrm{~nm}$, respectively), and e, f TEM images of the free-standing HPCM-NP (Scale Bar, $100 \mathrm{~nm}$ and $20 \mathrm{~nm}$, respectively). $\mathbf{g}$ SEM image (Scale Bar, $15 \mu \mathrm{m}$ ) and the corresponding elemental mapping of the iodine loaded HPCM-NP

carbon skeleton ${ }^{34,} 35$, enhancing the electrochemical performance.

As shown in Fig. 2a, the adsorption of iodine on all the carbon materials investigated in this study followed the same trend: initially increased with increasing time and then leveled off at the equilibrium point. The time to reach the adsorption equilibrium was around 7, 7, 5, and $3 \mathrm{~h}$ for HPCM-NP, NPCF, CC, and AC, respectively, and the adsorption capacity at equilibrium decreased from 125 to $50 \mathrm{wt} \%$ along the same order (The mass ratio of iodine is normalized to carbon). For AC, the equilibrium was reached rapidly due to the surface-dominated adsorption. In contrast, the adsorption process of iodine on hierarchically porous HPCM-NP is relatively slow ${ }^{15}, 35$, but achieves a large adsorption capacity. X-ray diffraction (XRD) pattern reveals the presence of broad peaks at around $24.5^{\circ}$ and $43.6^{\circ}$ attributable to the (002) and (101) diffraction peaks of graphitic cabons (Supplementary Fig. 9a). However, no diffraction peak of the loaded iodine is observed, suggesting the formation of noncrystalline iodine $\mathrm{e}^{15,34,35}$. The pronounced Raman D and G bands ( 1355 and $1596 \mathrm{~cm}^{-1}$, Supplementary Fig. 9b) are ascribed to the disordered carbon and graphitic $s p^{2}$ carbon, respectively. The $I_{\mathrm{D}} / I_{\mathrm{G}}$ Raman peak intensity ratios were found to be $1.5,1.4,1.3,1.2$, and 1.0 for the $I_{2}$-HPCM-NP, $I_{2}$-NPCF, iodine-nitrogen doped porous carbon cloth ( $\mathrm{I}_{2}-\mathrm{NCC}$, see Methods), $\mathrm{I}_{2}$-CC, and $\mathrm{I}_{2}$-AC, respectively. Thus, it was evident that the formation of highly porous structure and the introduction of heteroatom dopings led to an increased number of edges and surface defects ${ }^{13}$, which most likely improved the iodine adsorption and battery performance ${ }^{13,25,26}$. In consistence with the XRD data, Raman spectroscopy reveals no iodine peak, indicating, once again, the formation of amorphous iodine ${ }^{34,36}$.

Nitrogen adsorption-desorption isotherms show a sharp adsorption slope at $P / P_{0}<0.1$, suggesting the presence of micropores (Fig. 2b and Supplementary Fig. 10). The corresponding pore size distribution curve for HPCM-NP further confirms the presence of micropores with a narrow size distribution (centered at $\sim 1.7 \mathrm{~nm}$, Fig. $2 \mathrm{c}$ ), attractive for iodine adsorption ${ }^{33}$, 35. Nevertheless, the uptake of iodine led to a significantly decreased specific surface area (i.e., $973 \mathrm{~m}^{2} \mathrm{~g}^{-1}$, vs. $1487 \mathrm{~m}^{2} \mathrm{~g}^{-1}$ for pure HPCM-NP). The same tendency was also observed for other carbon materials $\left(1102,478,855\right.$, and $205 \mathrm{~m}^{2} \mathrm{~g}^{-1}$ for the $\mathrm{NPCF}, \mathrm{I}_{2}$-NPCF, CC, and $\mathrm{I}_{2}$-CC, respectively). More importantly, the pore size gradually decreased with increasing amount of the adsorbed iodine (Fig. 2c). These results indicate the adsorption/ infiltration/accumulation of iodine into the pores 34,36 . With the iodine loading increased up to $\sim 48 \mathrm{wt} \%$, the specific surface area 

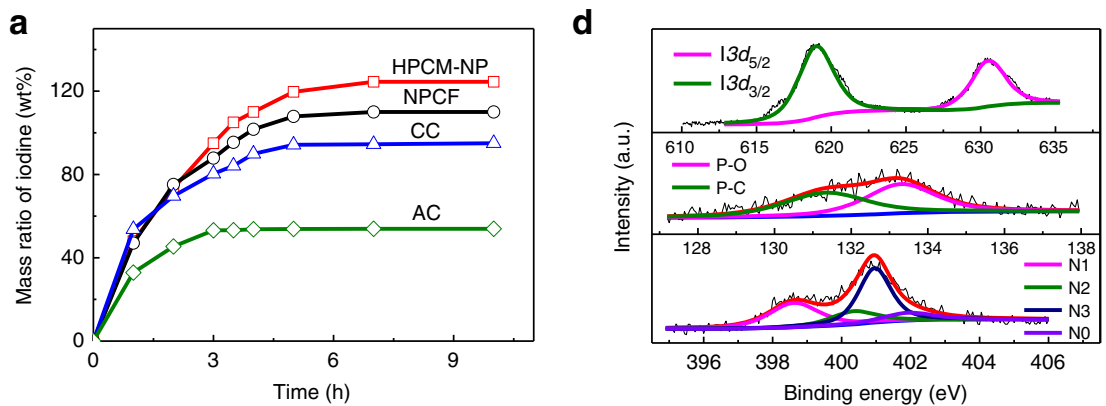

$\mathbf{g}$
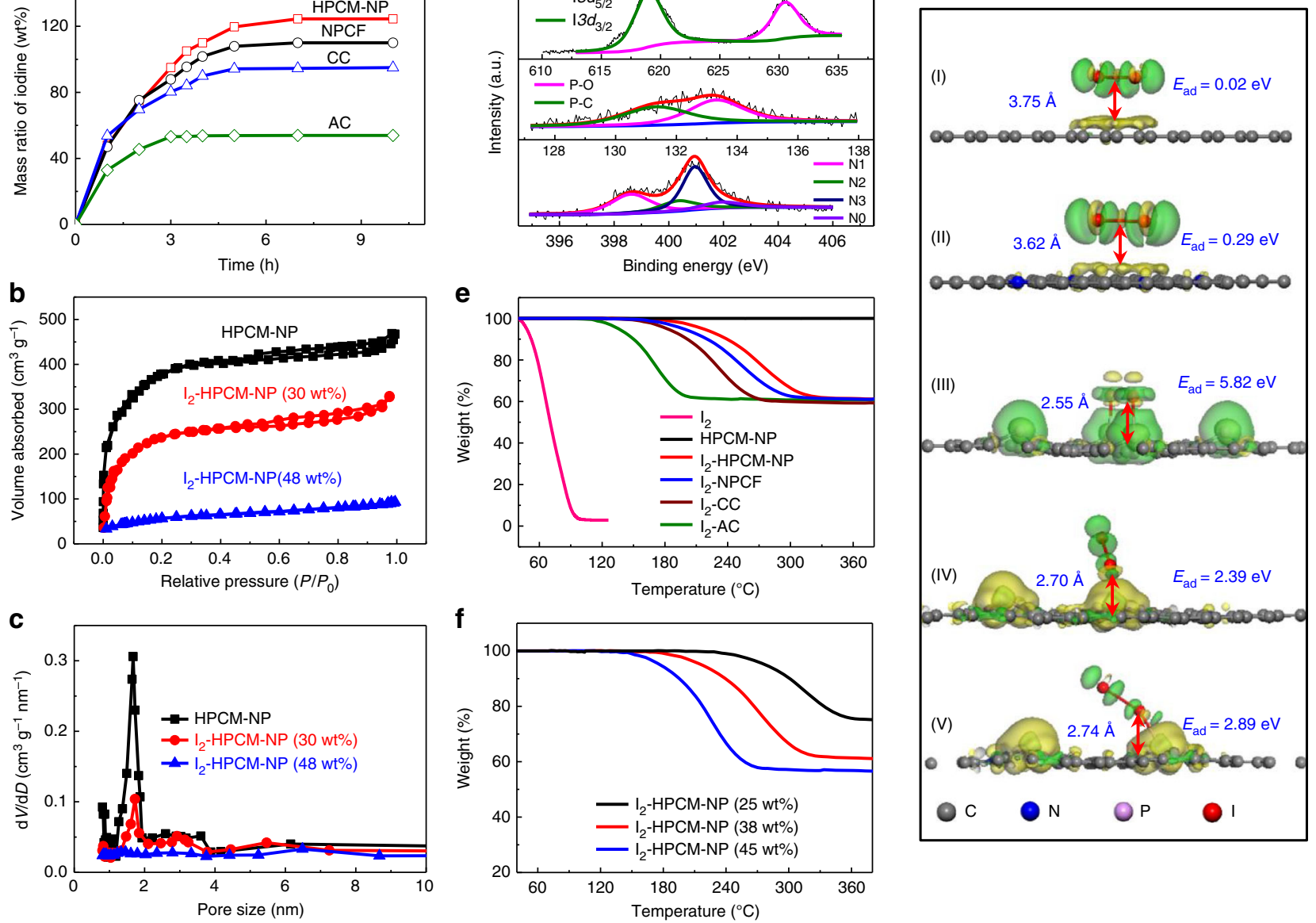

Fig. 2 Compositional characterization and stability analysis of iodine-carbon composites. a The time-dependent profiles for the mass ratio of iodine adsorbed on various carbons (the mass ratio is normalized to the mass of carbon). $\mathbf{b} \mathrm{N}_{2}$ adsorption-desorption isotherms and $\mathbf{c}$ the corresponding pore size distribution curves of HPMC-NP with different mass loading of iodine. $\mathbf{d}$ High-resolution XPS spectra of N1s, P2p, and I3d for $\mathrm{I}_{2}$-HPCM-NP samples. Thermogravimetric analysis curves of e pure iodine and iodine-carbon composites (iodine content, $40 \mathrm{wt} \%$ ), and $\mathbf{f} \mathrm{I}_{2}$-HPCM-NP composite with different iodine content. $\mathbf{g}$ The contour plots of the difference in charge density for the optimized structures of iodine molecule adsorbed on graphene $\mathrm{I}_{\text {, graphene }}$ doped with $\mathrm{N}(\mathrm{II}), \mathrm{P}(\mathrm{III})$, isolated $\mathrm{N}$ and $\mathrm{P}(\mathrm{IV})$, and coupled $\mathrm{N}$ and $\mathrm{P}(\mathrm{V})$. The differential charge density was calculated from: $\Delta \rho=\rho_{12}-\rho_{1}-\rho_{2}$, where $\rho_{1}, \rho_{12}$ and $\rho_{2}$ are the chare density of iodine, doped graphene with and without iodine adsorbed on the surface, respectively. Yellow and green color indicate the charge depletion and accumulation, respectively. The adsorption energies for $I_{2}$ molecule on these fragments were obtained using: $E_{\text {ad }}=-\left(E_{1}+E_{2}-E_{12}\right)$, where $E_{a d}$ is the adsorption energy of the $I_{2}$ molecule on the corresponding surfaces, $E_{1}$ is the total energy of the graphene (or heteroatom doped graphene), $E_{2}$ is the energy of one isolated $I_{2}$ molecule, and $E_{12}$ is the energy of the optimized structures for $I_{2}$ molecules adsorbed on the graphene planes. The bond lengths and heights of adsorbed $\mathrm{I}_{2}$ molecule are also listed in the figure, along with the corresponding adsorption energies

of HPCM-NP decreased from 1487 to $85 \mathrm{~m}^{2} \mathrm{~g}^{-1}$ (Fig. 2b) with an containment decrease in the volume fraction of micropores (Fig. 2c).

$\mathrm{X}$-ray photoelectron spectroscopy (XPS) survey spectra reveal the presence of C, N, P (Supplementary Fig. 11a), confirming the formation of nitrogen and phosphorus co-doped carbon for HPCM-NP. As expected, the presence of some oxygen $(5.1 \%)$ cannot be ruled out ${ }^{25}$. High-resolution N1s XPS spectrum of HPCM-NP (Fig. 2d) can be convoluted into four peaks centered at $\sim 398.6,400.5,401.3$ and $402.0 \mathrm{eV}$ corresponding to pyridinic $(\mathrm{N} 1)$, pyrrolic (N2), graphitic (N3), and oxidized pyridinic (N0) nitrogen $^{13,25,37}$, respectively. The fitted P2p peaks of HPCM-NP located at 131.8 and $133.4 \mathrm{eV}$ can be assigned to the P-C and P-O bonds 25,26 . Upon the iodine uploading, three peaks centered at 48.5, 619.2, and 630.6 eV were observed (Supplementary Fig. 11b), attributable to $\mathrm{I} 4 d, \mathrm{I} 3 d_{5 / 2}$ and $\mathrm{I} 3 d_{3 / 2}$ of iodine (Fig. $\left.2 \mathrm{~d}\right)^{15}$. The obvious binding energy shift in comparison with the pure iodine suggests the strong interaction of iodine with the carbon substrate (Supplementary Fig. 12 and Supplementary Note 3). According to the theoretical results (Supplementary Fig. 13), the charge modulation due to the nitrogen and phosphorus doping would contribute to the binding shift, which could also enhance the stability of iodine adsorbed ${ }^{15,25,38}$.

The thermal gravimetric analysis (TGA) profile of pure iodine shows the evaporation of iodine blow $80^{\circ} \mathrm{C}$ due to its low sublimation temperature (Fig. 2e). Compared with pure iodine, iodine-adsorbed HPCM-NP ( $\mathrm{I}_{2}$-HPCM-NP) sample shows an increased temperature range $\left(120-200^{\circ} \mathrm{C}\right)$ for iodine evaporation, indicating the strong interaction of iodine with the porous $\mathrm{N}, \mathrm{P}$ co-doped carbon scaffold ${ }^{34}, 39 . \mathrm{I}_{2}$-HPCM-NP exhibited the highest on-set evaporation temperature at around $200{ }^{\circ} \mathrm{C}$, suggesting the best thermal stability of adsorbed iodine on the HPCM-NP, followed by $\mathrm{I}_{2}$-NPCF $\left(\sim 180^{\circ} \mathrm{C}\right), \mathrm{I}_{2}$-CC $\left(\sim 150^{\circ} \mathrm{C}\right)$, and $\mathrm{I}_{2}-\mathrm{AC}\left(\sim 120^{\circ} \mathrm{C}\right)$. The enhanced thermal stability for the uploaded iodine could lead to a better cycling stability of relevant batteries $^{15}$. For $\mathrm{I}_{2}$-HPCM-NP, the on-set temperature for iodine evaporation significantly decreased from $\sim 250$ to $150{ }^{\circ} \mathrm{C}$ with increasing iodine loading (Fig. 2f). Our theoretical calculation 

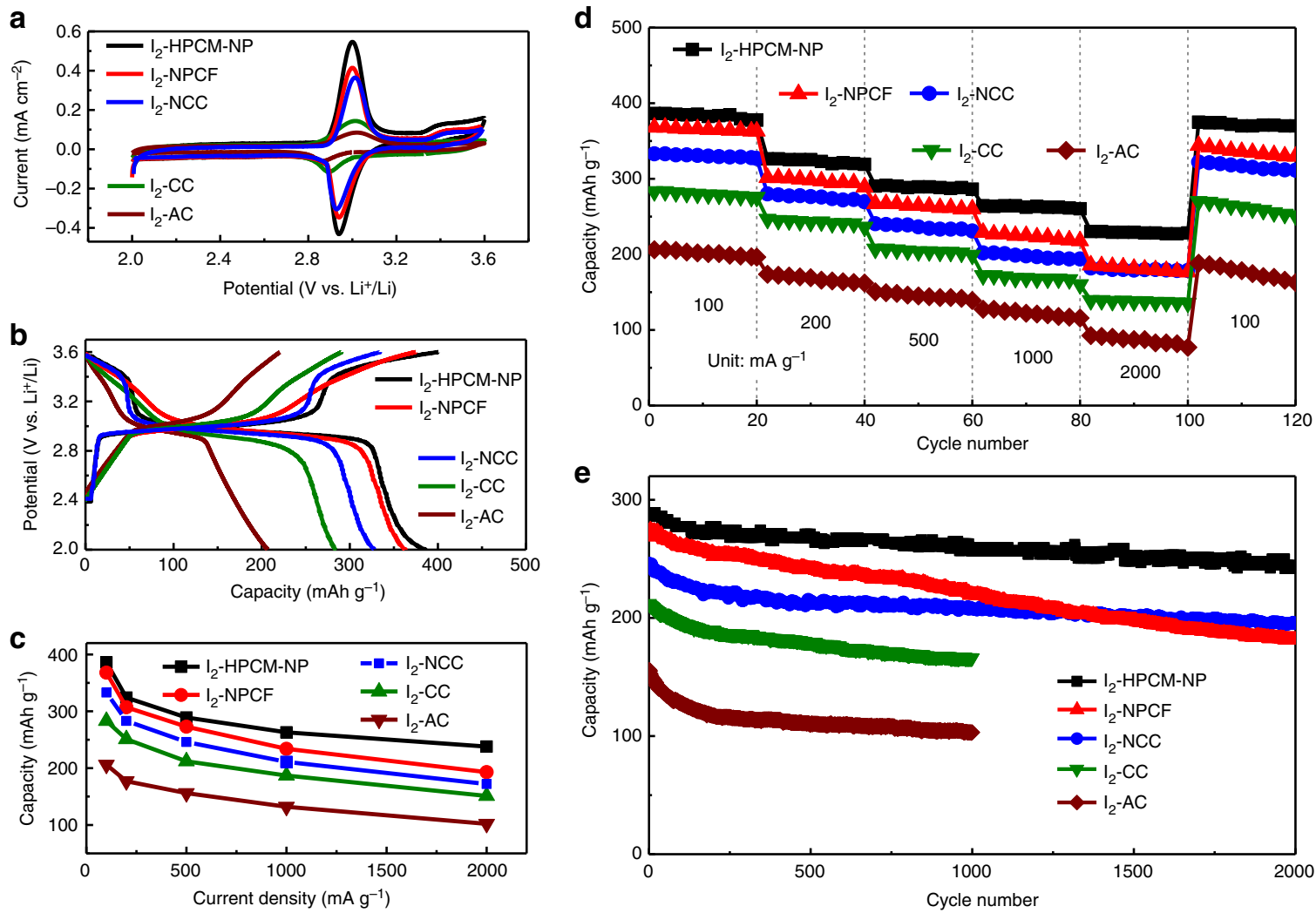

Fig. 3 Electrochemical performance of different iodine cathodes for $\mathrm{Li}-\mathrm{I}_{2}$ batteries. a Cyclic voltammograms $\left(0.1 \mathrm{mV} \mathrm{s}{ }^{-1}\right)$, b charge/discharge voltage profiles $\left(100 \mathrm{~mA} \mathrm{~g}^{-1}\right)$, and $\mathbf{c}$ specific discharge capacities of different iodine-carbon cathodes between 2.0 and $3.6 \mathrm{~V}$ with the same iodine loading of $2.0 \mathrm{mg} \mathrm{cm}^{-2}$. d Rate capability and $\mathbf{e}$ cycling stability tests of iodine-carbon cathodes at a current density of $500 \mathrm{~mA} \mathrm{~g}^{-1}$

reveals that the strong interaction between iodine and graphene can be achieved via $\mathrm{N}$ and $\mathrm{P}$ doping (Fig. $2 \mathrm{~g}$, explained in detail in Supplementary Fig. 13 and Supplementary Note 4). Specifically, the synergic effect of $\mathrm{N}$ and $\mathrm{P}$ co-doping significantly improves the adsorption energy $\left(E_{\mathrm{ad}}\right)$, which will enhance the stability of iodine adsorbed. Furthermore, the strong interactions toward iodine would also benefit to the nucleation of iodine by lowering the surface tensile against the carbon substrate, leading to the high iodine loading $24,40-42$. With increasing iodine loading, however, more and more iodine molecules aggregated in the pores without directly supported by the carbon surface, resulting in the poorer thermal stability (Supplementary Fig. 14). Therefore, hierarchically porous structure and heteroatom doping are crucial for the stability of adsorbed iodine, which would contribute to the battery performance and it's cycling stability.

Electrochemical performance of lithium-iodine battery. Cyclic voltammogram $(\mathrm{CV})$ curves show a support-dependent property for various iodine loaded carbon electrodes (Fig. 3a). The welldefined redox peaks in each CV curve indicate a two-step redox process of iodine-carbon composite electrodes. The sharp peak at about $3.0 \mathrm{~V}$ and a hump at around $3.4 \mathrm{~V}$ correspond to the oxidation of $\mathrm{LiI}$ to $\mathrm{LiI}_{3}$ and then to higher-order elemental iodine, respectively. In contrast, the cathodic peaks centered at $\sim 2.9$ and $3.3 \mathrm{~V}$ arise from the reversible conversion pairs of $\mathrm{LiI}_{3} / \mathrm{LiI}$ and $\mathrm{I}_{2} / \mathrm{LiI}_{3}{ }^{14,15}$. The differential capacity plot (Supplementary Fig. 15) also confirms the two-step process for the redox reactions. The good linear relationship between the peak current $\left(i_{\mathrm{p}}\right)$ and the square root of scan rates for $\mathrm{LiI}_{3} / \mathrm{LiI}$ redox pair (Supplementary Fig. 16) suggests a diffusion-controlled redox process ${ }^{14}$. In contrast, the oxidation current of $\mathrm{I}_{3}{ }^{-}$converted to elemental iodine is directly proportional to the value of the scan rates, and thus the ion diffusion is quick and its redox kinetic is only limited by electron transfer. Obviously, the pseudocapacitive character is involved in the redox process of iodine, which would be favorable for both high capacity and high-rate performance ${ }^{14}, 15,18$.

Notably, the $\mathrm{I}_{2}$-HPCM-NP electrode shows the largest current density with good reversibility and the peak potential difference $\left(\Delta E_{\mathrm{p}}\right)$ of the redox peaks is only $88 \mathrm{mV}$ (Fig. 3a). In contrast, the $\Delta E_{\mathrm{p}}$ of $\mathrm{I}_{2}-\mathrm{NPCF}, \mathrm{I}_{2}-\mathrm{NCC}, \mathrm{I}_{2}-\mathrm{CC}$, and $\mathrm{I}_{2}-\mathrm{AC}$ is around 91,135 , 170 , and $220 \mathrm{mV}$, respectively. The observed remarkably large current density and good reversibility for the $\mathrm{I}_{2}$-HPCM-NP could be attributated, once again, to the synergistic effect of $\mathrm{N}, \mathrm{P}$ codoping to introduce more edge/active defects with respect to other carbon hosts $25,43,44$. As revealed by the experimental and theoretial results (Supplementary Figs. 13, 17, 18 and Supplementary Note 5), the strong anchoring effect could not only accelerate the nucleation of iodine and enable fast kinetics according to the basical growth behavior of nanostructures, but also stablize iodine and $\mathrm{LiI}_{3}$ to retard the shuttle effect, thus improving the reversibility and cycling stability ${ }^{14,15,34}$. Therefore, a rational design and controllable construction of the carbon electrode is essential to enhance the overall performance of the electrode materials ${ }^{13,34}$.

The typical galvanostatic charge/discharge curves (Fig. 3b) of the Li-iodine battery using different iodine-carbon cathodes exhibit two voltage slops at 3.3-3.5, 2.9-3.1 V for charging curves and $3.2-3.4,2.8-3.0 \mathrm{~V}$ for discharging curves. The good symmetric charge/discharge profile for $\mathrm{I}_{2}$-HPCM-NP electrode with high Coulombic efficiency (CE) suggests a good reversibility. At the current density of $100 \mathrm{~mA} \mathrm{~g}^{-1}$, the $\mathrm{I}_{2}$-HPCM-NP electrode delivered the largest initial discharge capacity of $386 \mathrm{mAh} \mathrm{g}^{-1}$ and charge capacity of $391 \mathrm{mAh} \mathrm{g}^{-1}$ with a high 
CE of $98.7 \%$ and high symmetry (Fig. $3 \mathrm{~b}$ and Supplementary Fig. 19). Such a high capacity is even larger than the theoretical capacity $\left(211 \mathrm{mAh} \mathrm{g}^{-1}\right)$ for Li-iodine batteries ${ }^{14}, 15$. This is because the pure HPCM-NP would also contribute to the whole capacity of $\mathrm{I}_{2}$-HPCM-NP due to the capacitive contribution $(\sim 56$ $\mathrm{mAh} \mathrm{g}^{-1}$ in Supplementary Fig. 20, the details in Supplementary Note 6) ${ }^{14}$, 15 . Notably, the specific capacity of $\mathrm{I}_{2}$-HPCM-NP decreased with increasing the iodine loading (Supplementary Fig. 21) since not all iodine participated in the redox reactions at high loadings. At the mass loding of $2 \mathrm{mg} \mathrm{cm}^{-2}$, the calculated discharge capacities for $\mathrm{I}_{2}$-HPCM-NP, $\mathrm{I}_{2}-\mathrm{NPCF}, \mathrm{I}_{2}-\mathrm{NCC}, \mathrm{I}_{2}-\mathrm{CC}$ and $\mathrm{I}_{2}-\mathrm{AC}$ at different current densities from 100 to $2000 \mathrm{~mA} \mathrm{~g}^{-1}$ are summarized in Fig. $3 \mathrm{c}$.

The initial specific capacities for $\mathrm{I}_{2}-\mathrm{NPCF}, \mathrm{I}_{2}-\mathrm{NCC}, \mathrm{I}_{2}-\mathrm{CC}$, and $\mathrm{I}_{2}-\mathrm{AC}$ cathodes are around $368,331,283$, and $206 \mathrm{mAh} \mathrm{g}^{-1}$, respectively, at a current density of $100 \mathrm{~mA} \mathrm{~g}^{-1}$. These capacities decreased to $238,179,151$ and $102 \mathrm{mAh} \mathrm{g}^{-1}$ when the current density increased to $2000 \mathrm{~mA} \mathrm{~g}^{-1}$, corresponding to a capacity fade of $35.3,45.9,46.6$, and $50.5 \%$. Notably, a good capacity retention of $70.7 \%$ was observed for $\mathrm{I}_{2}$-HPCM-NP after a total of 100 cycles at the increased current density from 100, 200, 500, 1000 to $2000 \mathrm{~mA} \mathrm{~g}^{-1}$ (20 consective cycles at each of the current densities; Fig. 3d). Thereafter, the capacity can be recovered to $375 \mathrm{mAh} \mathrm{g}^{-1}$ with a capacity retention of $97.2 \%$ by switching the current denisty back to $100 \mathrm{mAg}^{-1}$, which is better than the corresponding values for other composite electrodes (96.7, 93.5, 95.4, and $91.3 \%$ capacity retention for $\mathrm{I}_{2}-\mathrm{NCC}, \mathrm{I}_{2}-\mathrm{NPCF}, \mathrm{I}_{2}-\mathrm{CC}$, and $\mathrm{I}_{2}-\mathrm{AC}$, respectively). The $3 \mathrm{D}$ hierarchical porous framework not only allows for the electrolyte to easily access into the inner surface but also ensures effective electronic transport along the conductive carbon skeleton (Supplementary Fig. 22 and Supplementary Note 7). Thus, the improved rate capability for the $\mathrm{I}_{2}$ HPCM-NP can be achieved. Besides, $\mathrm{I}_{2}$-HPCM-NP samples obtained at various temperatures $600-1000{ }^{\circ} \mathrm{C}$ exhibited increased specific capacity from 215 to $295 \mathrm{mAh} \mathrm{g}^{-1}$ with increasing temperature (Supplementary Fig. 23), possibly due to the
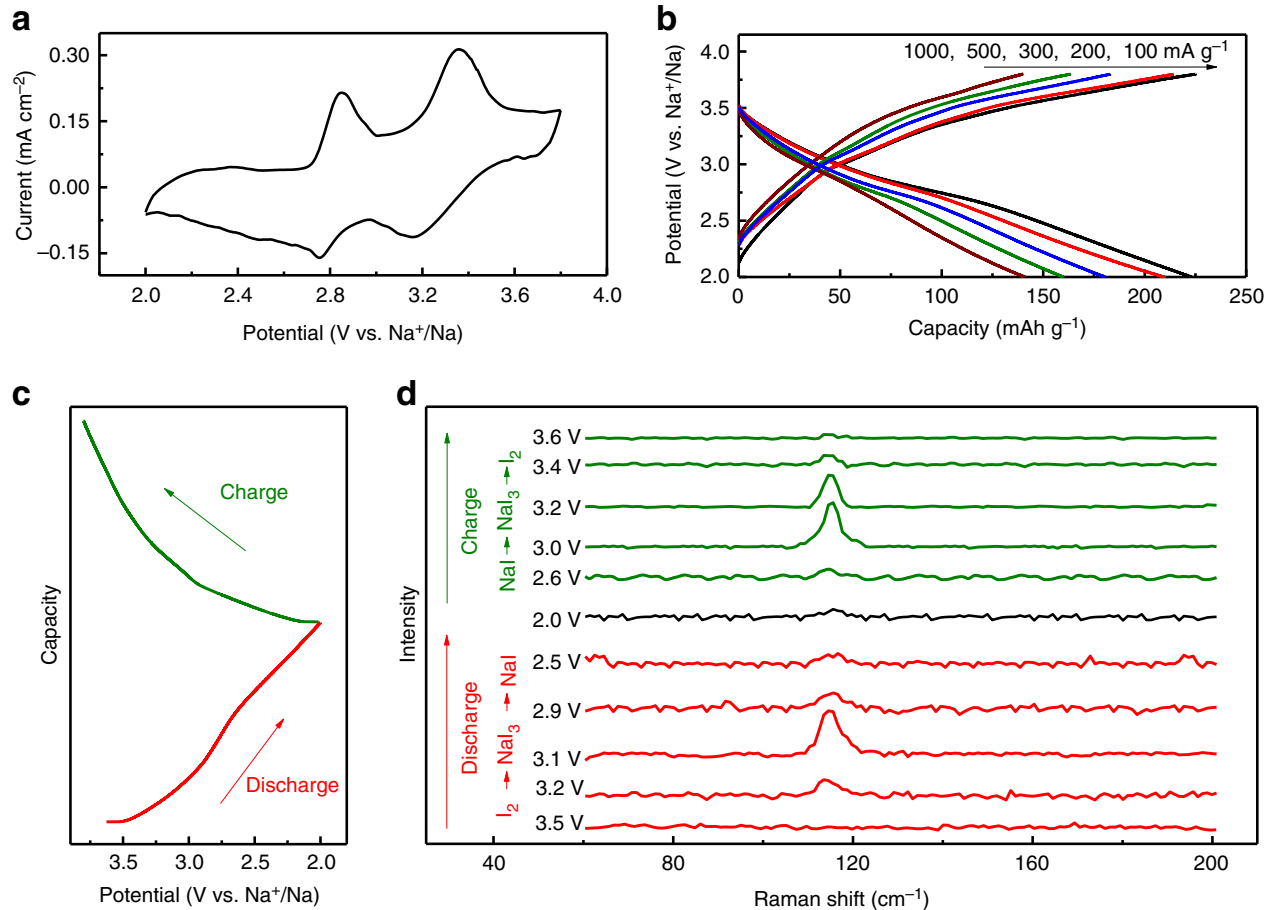

Fig. 4 Electrochemical performance of $\mathrm{I}_{2}$-HPCM-NP cathode for a Na- $\mathrm{I}_{2}$ battery. $\mathbf{a} \mathrm{CV}$ curve $\left(0.1 \mathrm{mV} \mathrm{s}^{-1}\right)$ and $\mathbf{b}$ representative charge/discharge curves of $\mathrm{I}_{2}$-HPCM-NP cathode for $\mathrm{Na}_{2} \mathrm{I}_{2}$ battery. $\mathbf{c}$ Discharge and charge curves with the test positions for analysis. $\mathbf{d}$ In situ Raman analyses of Na-I $\mathrm{I}_{2}$ batteries at different discharge and charge stages

formation of graphitic carbon with a good electric conductivity at high pyrolysis temperatures ${ }^{13,25}$. A long-term cycling stability test for $\mathrm{I}_{2}$-HPCM-NP revealed a capacity retention of $84.5 \%$ after 2000 charge/discharge cycles $(79.4$ and $66.3 \%$ capacity retention after 2000 cycles for $\mathrm{I}_{2}$-NCC and $\mathrm{I}_{2}$-NPCF; 78.3 and $66.0 \%$ capacity retention after 1000 cycles for $\mathrm{I}_{2}-\mathrm{CC}$ and $\mathrm{I}_{2}-\mathrm{AC}$ ), sugesting the good cycling stability (Fig. 3e). The cycling formance of $\mathrm{I}_{2}$-HPCM-NP is thus comparable to many other similar iodine cathodes in the literature (Supplementary Table 1) 18, 19 . It is revealed a slow dissolution of iodine into the trolyte (Supplementary Fig. 24 and Supplementary Note 8) during the cycling test and no obvious side reaction of the electrolyte is observed except the revisible redox of iodine over potential range tested (Supplementary Fig. 25 and Supple(hote 9). However, the gradual formation of Li dendritics on the Li-metal electrode (Supplementary Fig. 26 and Supplementary Note 10) could slightly deteriorate the battery stablity. In to the strong anchoring effect of heteroatom doping, the dhe rationalof 3D PANi aerogel on a carbon fiber substrate without nonconductive binders, which provides abundant electrode/ electrolyte contact interfaces and reduces ion diffusion path for fectrochemical kinetics (Supplementary Fig. 22) 13, 24, 25, 34 for those reported binder-added electrodes, inevitable, arising from the insulating, inactive, and easily swelling polymeric binders ${ }^{45}$.

Electrochemical performance of sodium-iodine battery. To exploit the broad applications for the iodine-carbon cathodes, $\mathrm{I}_{2}$-HPCM-NP electrode was also coupled with $\mathrm{Na}$ metal to fabricate a $\mathrm{Na}-\mathrm{I}_{2}$ battery. The CV curve (Fig. 4a) exhibits a two-step redox process. Typically, the two cathodic peaks located at 3.15 and $2.76 \mathrm{~V}$ could be ascribed to the sequential reduction 

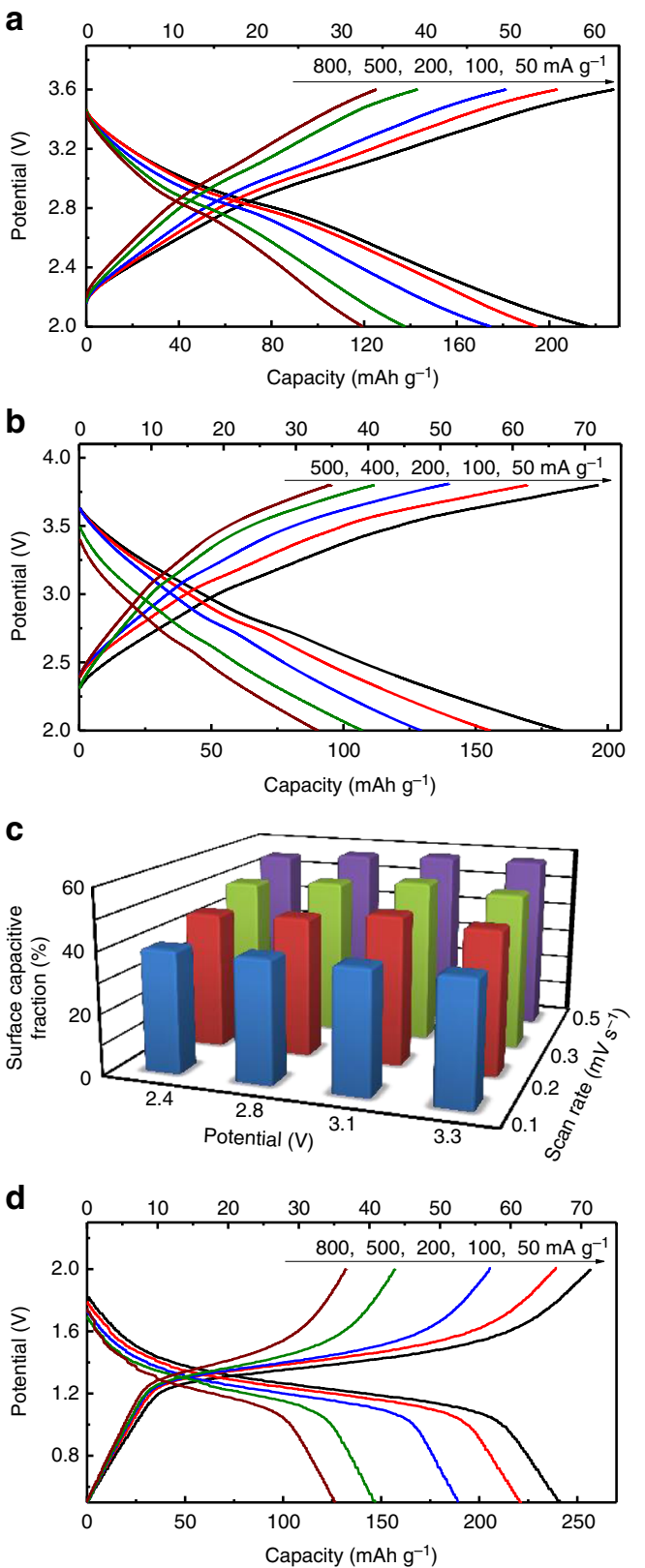
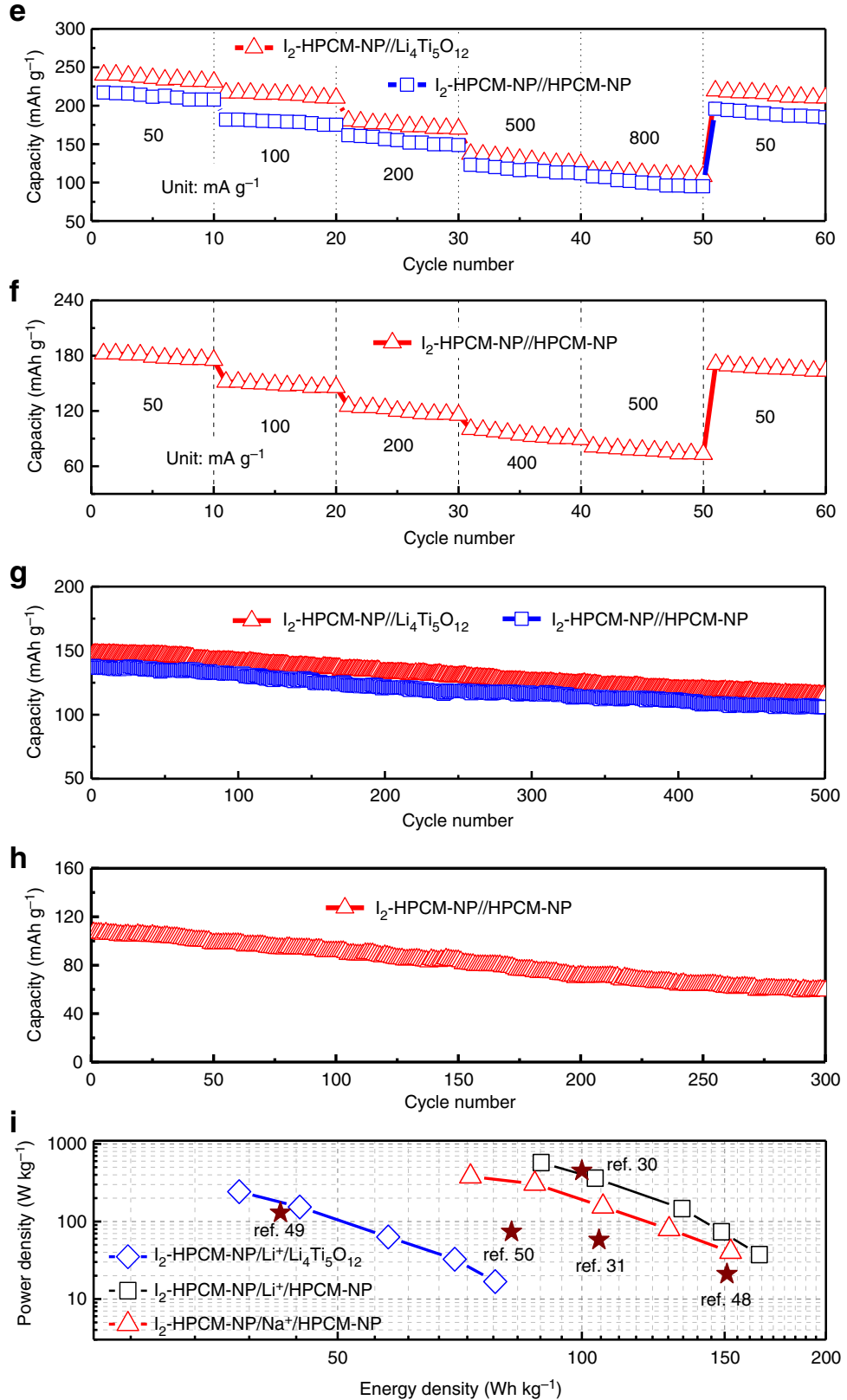

Fig. 5 Electrochemical performance of iodine-carbon hybrid full battery. Charge/discharge curves at different rates of $\mathrm{I}_{2}-\mathrm{HPCM}-\mathrm{NP} / / \mathrm{HPCM}-\mathrm{NP}$ in a LiTFSI and $\mathbf{b ~} \mathrm{NaClO}_{4}$, respectively, and the corresponding discharge capacities (up: based on the weight of anode and cathode; down: based on the weight of carbon-based electrodes). c Surface pseudocapacitance (redox) contributions at different conditions. d Charge/discharge curves at different rates of $\mathrm{I}_{2}-\mathrm{HPCM}-\mathrm{NP} / / \mathrm{Li}_{4} \mathrm{Ti}_{5} \mathrm{O}_{12}$ full battery and the corresponding discharge capacities (up: based on the weight of anode and cathode; down: based on the weight of carbon-based electrodes). e, $\mathbf{f}$ Rate capability and $\mathbf{g}$, $\mathbf{h}$ cycling performance of different hybrid full batteries with $\mathbf{e}, \mathbf{g} \mathrm{LiTFSI}$ and $\mathbf{f}, \mathbf{h} \mathrm{NaClO}$. i Ragone plot of full batteries, where power and energy densities are estimated based on the total mass of cathode and anode materials

transitions of $\mathrm{I}_{2} / \mathrm{I}_{3}{ }^{-}$and $\mathrm{I}_{3}{ }^{-} / \mathrm{I}^{-}$with the insertion of $\mathrm{Na}^{+}$ions. In the reverse process, the two anodic peaks are ascribed to the oxidation of $\mathrm{NaI}$ to $\mathrm{NaI}_{3}$ at $2.75 \mathrm{~V}$ and the subsequent oxidation to $\mathrm{I}_{2}$ at $3.16 \mathrm{~V}^{16}$. The typical charge/discharge curves (Fig. $4 \mathrm{~b}$ ) reveal that the specific capacity is $224,200,171,156$ and $137 \mathrm{mAh} \mathrm{g}^{-1}$ at a current density of 100, 200, 300, 500 and $1000 \mathrm{~mA} \mathrm{~g}^{-1}$, respectively. The specific capacity is smaller than that of Li- $\mathrm{I}_{2}$ battery at the same current density (vide supra) due to the larger ion radius and slower diffusion kinetics for $\mathrm{Na}^{+}$ ions ${ }^{12}, 13,16,28$. To gain deep insight into the energy storage process in a Na- $\mathrm{I}_{2}$ battery, we performed in-situ Raman measurements at various discharging/charging stages (Figs. $4 c, d$ ). During the discharge process, a characteristic peak at about
$115 \mathrm{~cm}^{-1}$ emerged and gradually became more intense as the reaction progressed. This peak could be ascribed to the symmetric stretching mode of $\mathrm{I}_{3}{ }^{-}$, corresponding to the conversion of $\mathrm{I}_{2}$ to $\mathrm{I}_{3}^{-}$along with the insertion of $\mathrm{Na}^{+}$ions ${ }^{15}, 16$. With further decreasing potential to $2.0 \mathrm{~V}$, the gradually disappeared peak indicated the reaction transformation of $\mathrm{NaI}_{3}$ to $\mathrm{NaI}$ at the second reaction step. Therefore, it was evident that the reversible reactions occurred during the discharging/charging processes via $2 \mathrm{Na}+\mathrm{I}_{2} \leftrightarrow 2 \mathrm{NaI}$ with the formation of $\mathrm{NaI}_{3}$ as an intermediate ${ }^{14-}$ 16. These results indicate that the redox behaviors of iodine and sodium couple is quite similar to those of $\mathrm{Li}-\mathrm{I}_{2}$ battery. When the current density was increased by ten times $\left(100\right.$ to $\left.1000 \mathrm{~mA} \mathrm{~g}^{-1}\right)$, a capacity retention of $\sim 61.2 \%$ was obtained and $\sim 93.8 \%$ of the 
initial discharge capacity $\left(210 \mathrm{mAh} \mathrm{g}^{-1}\right)$ can be recovered when the current was restored to $100 \mathrm{~mA} \mathrm{~g}^{-1}$ (Supplementary Fig. 27a), suggesting a good rate-performance. Besides, the $\mathrm{Na}-\mathrm{I}_{2}$ battery retained $85 \%$ of its initial discharge capacity over 500 charge/ discharge cycles (Supplementary Fig. 27b), exhibiting also a good cycling stability ${ }^{14-16,19}$.

Electrochemical performance of iodine-carbon full batteries. As demonstrated above, the specific capacity of $\mathrm{Li}-\mathrm{I}_{2}$ battery is larger than that of $\mathrm{Na}-\mathrm{I}_{2}$ battery, though the same $\mathrm{I}_{2}$-carbon cathode was used. Therefore, the ion intercalation at the carbon electrode should have a significant influence on its specific capacity, presumably due to the different sizes between $\mathrm{Li}$ and $\mathrm{Na}$ ions ${ }^{15}, 16$. When used as anodes in LIBs, the first discharging capacities are around $388,375,369,211$, and $163 \mathrm{mAh} \mathrm{g}^{-1}$ for HPCM-NP, NPCF, NCC, CC, and AC (Supplementary Fig. 28), respectively. The observed good performance of the HPCM-NP anode (Supplementary Fig. 29 and Supplementary Note 11) is comparable to and even better than those of other carbon-based anodes (see Supplementary Table 2), particularly coupled with $\mathrm{LiMn}_{2} \mathrm{O}_{4}$ and $\mathrm{Na}_{3} \mathrm{~V}_{2}\left(\mathrm{PO}_{4}\right)_{3} / \mathrm{C}$ cathodes (Supplementary Fig. 30 and Supplementary Note 12) in full batteries using $\mathrm{Li}^{+} / \mathrm{Na}^{+}$ion containing electrolytes (Supplementary Fig. 31). These results indicate that HPCM-NP can be also used as anodes in Li/Na-ion batteries based on ion intercalation process, and, if coupled with the $\mathrm{I}_{2}$-HPCM-NP cathode, a metal-electrode-free iodine-carbon full battery can be developed by using $\mathrm{Li}^{+} / \mathrm{Na}^{+}$-containing electrolytes.

To further incorporate the redox reactions of iodine with the intercalation process, a full battery is fabricated by coupling $\mathrm{I}_{2}$-HPCM-NP cathode with HPCM-NP ( $\mathrm{I}_{2}$-HPCM-NP//HPCM$\mathrm{NP}$ ) anode in a Li- or Na-ion electrolyte, which is free from the $\mathrm{Li}$ or Na metal anode, and hence without the associated safety risk ${ }^{7}$. The charge/discharge curves of $\mathrm{I}_{2}$-HPCM-NP//HPCM-NP exhibited relatively smooth profiles without obvious discharge plateaus for both the $\mathrm{Li}$ (LiTFSI, Fig. 5a)- and $\mathrm{Na}\left(\mathrm{NaClO}_{4}\right.$, Fig. 5b)- ion electrolyte. The discharge capacity at the current density of $50 \mathrm{~mA} \mathrm{~g}^{-1}$ is $217,182 \mathrm{mAh} \mathrm{g}^{-1}$ in a Li-, Na-ion electrolyte, respectively. The typical CV curves with a couple of redox peaks (Supplementary Fig. 32) show the redox behaviour of iodine coupled with insertion/extraction of $\mathrm{Li}^{+}$ions. To clarify the contributions of both processes, the fractions of redox capacitive and diffusion-controlled contributions to charge storage were determined (Fig. 5c) ${ }^{46,47}$. At a low scan rate of $0.1 \mathrm{mV} \mathrm{s}^{-1}$, the pseudocapacitive contribution was only $40 \%$, indicating that $\sim 60 \%$ of the total stored charge was on the basis of the ion intercalation process at a specific potential (e.g., $2.8 \mathrm{~V}$ ). However, the ratio increased to $\sim 57 \%$ at a high scan rate of $0.5 \mathrm{mV} \mathrm{s}^{-1}$. These results indicate the higher pseudocapacitive contribution renders the better high-rate performance as the ion intercalation process needs a longer time to achieve ${ }^{46,47}$. The almost equal contributions $(\sim 50 \%)$ for the both processes seen in Fig. $5 \mathrm{c}$ suggests that the energy storage of a metal-electrode-free iodinecarbon full battery can be modulated by adjusting both redox reactions of iodine and cation intercalation - a plausible concept, but one which has not yet been realized. To further verify the feasibility, HPMC-NP was replaced with a typical zero-strain intercalative anode, $\mathrm{Li}_{4} \mathrm{Ti}_{5} \mathrm{O}_{12}$ (Supplementary Fig. 33), in the full cell (Fig. $5 \mathrm{~d}$ ). The CV curve of $\mathrm{I}_{2}$-HPCM-NP exhibited a pair of redox peaks of iodine located at around of $3.0 \mathrm{~V}$ whereas the peaks for $\mathrm{Li}_{4} \mathrm{Ti}_{5} \mathrm{O}_{12}$ located at around $1.5 \mathrm{~V}$ was ascribed to the reversible intercalation process of $\mathrm{Li}^{+}$ions (Supplementary Fig. 34). When coupled both electrodes in a full cell, a pair of redox peaks at around 1.42/1.27 $\mathrm{V}$ could be ascribed to the overall electrochemical reaction $\left(2 \mathrm{Li}_{4} \mathrm{Ti}_{5} \mathrm{O}_{12}+2 \mathrm{xLiI} \leftrightarrow 2 \mathrm{Li}_{4+\mathrm{x}} \mathrm{Ti}_{5} \mathrm{O}_{12}+\mathrm{I}_{2}\right)$, in which both redox reactions and the ion intercalation were coupled together, leading to a specific capacity of $240 \mathrm{mAh} \mathrm{g}^{-1}$ (Fig. 5d). The ratio of pseudocapacitive contribution over intercalative one at a given voltage is quantitatively determined according to the $\mathrm{CV}$ curves at various scan rates (Supplementary Fig. 35). The calculated capacity contribution from the surface pseudocapacitive is in the range of $41-64 \%$. This result implies a dominating diffusion-limited ion-intercalative process at slow scan rates whereas the surface redox reaction is restricted at a specific potential. Further quantitative capacitive analyses on the hybrid ion storage behavior indicate that the surface pseudocapacitive contribution increased from $41 \%$ to $61 \%$ with increasing the scan rate at a fixed potential $(1.45 \mathrm{~V})$ as the high scan rate could facilitate the pseudocapacitive process ( $c f$. Fig. $5 c$ ). These results support the concept to improve the performance of $\mathrm{I}_{2}$ HPCM-NP//HPCM-NP full batteries by the combination of iodine ion intercalation with its redox reactions.

According to the rate capability tests (Figs. 5e, f), the capacity retentions of $\mathrm{I}_{2}$-HPCM-NP//HPCM-NP and $\mathrm{I}_{2}$-HPCM-NP// $\mathrm{Li}_{4} \mathrm{Ti}_{5} \mathrm{O}_{12}$ after 50 cycles at various current densities from 50 to $800 \mathrm{~mA} \mathrm{~g}^{-1}$ (about 16 times increase) were about $49.9 \%(108.3$ $\mathrm{mA} \mathrm{h}{ }^{-1}$ ) and $48.0 \%\left(115.1 \mathrm{mAh} \mathrm{g}^{-1}\right)$, respectively (Fig. 5e). For the hybrid full battery in a Na-ion electrolyte, the capacity retentions of $\mathrm{I}_{2}$-HPCM-NP//HPCM-NP was approximately 44.6 $\%\left(81.1 \mathrm{mAh} \mathrm{g}^{-1}\right)$ after 50 cycles with the current densities increased by 10 times (increased from 50 to $500 \mathrm{~mA} \mathrm{~g}^{-1}$ ) (Fig. 5f). Furthermore, the hybrid full batteries exhibited good cycling stability with capacity retention of $\sim 74 \%$ for $\mathrm{I}_{2}$-HPCM-NP// HPCM-NP and $76 \%$ for $\mathrm{I}_{2}-\mathrm{HPCM}-\mathrm{NP} / / \mathrm{Li}_{4} \mathrm{Ti}_{5} \mathrm{O}_{12}$ after 500 cycles at a current density of $500 \mathrm{~mA} \mathrm{~g}^{-1}$ (Fig. $5 \mathrm{~g}$ ). In contrast, the battery in a $\mathrm{Na}$-ion electrolyte can deliver discharge capacity of $58.9 \mathrm{mAh} \mathrm{g}^{-1}$ with the initial capacity retention of $55.0 \%$ after 300 cycles at a current density of $400 \mathrm{~mA} \mathrm{~g}^{-1}$ (Fig. 5h). The good battery performance in Li-ion electrolyte could be contributed to the smaller size and the fast diffusion kinetics of $\mathrm{Li}$ ions ${ }^{13}, 16,36$. As can be seen from the Ragone plot (Fig. 5i), the power and energy densities of the metal-electrode-free iodine-carbon full batteries are comparable to and even better than recently reported $\mathrm{Li}$-ion or $\mathrm{Na}$-ion full batteries ${ }^{30}, 31,48-50$. Specifically, energy densities of $165.6 \mathrm{Wh} \mathrm{kg}^{-1}$ for the iodine-carbon battery using a Li-ion electrolyte and $152.6 \mathrm{Wh} \mathrm{kg}^{-1}$ for that using a $\mathrm{Na}$-ion electrolyte were achieved at the power densities of 37.4 and $40.4 \mathrm{~W} \mathrm{~kg}^{-1}$, respectively. When the electrolyte was included in the calculation, the energy density of full battery was around 27.8/ $27.0 \mathrm{Wh} \mathrm{kg}^{-1}$ in a Li-/Na-ion electrolyte at a power density of $6.5 /$ $7.3 \mathrm{~W} \mathrm{~kg}^{-1}$, respectively (Supplementary Fig. 36) because the weight ratio between the electrolyte and electrode materials was in the range of $4.5 \sim 5.0$. As shown in Supplementary Fig. 37, a red LED was powered on by an iodine-carbon full battery, which demonstrates that the combination of redox reactions and ion intercalation as an effective approach for the development of high-performance iodine-carbon rechargeable batteries from lowcost heteroatom-doped 3D porous carbon electrodes for efficient energy storage.

\section{Discussion}

In this study, we have prepared 3D free-standing porous carbon matrix co-doped with $\mathrm{N}$ and $\mathrm{P}$ by a facile pyrolysis of polyaniline coated cellulose wipers generated from interfacial polymerization of aniline on the cellulose wiper in the presence of phytic acid. Owing to the heteroatom-doped hierarchically porous carbon structure, iodine can be efficiently loaded up to a high content (125 wt\%), leading to the formation of free-standing iodine-carbon electrodes for fabricating rechargeable $\mathrm{Li}$ - and $\mathrm{Na}-\mathrm{I}_{2}$ batteries with high performance. Typically, the rechargeable $\mathrm{Li}-\mathrm{I}_{2}$ and 
$\mathrm{Na}-\mathrm{I}_{2}$ batteries manifested high discharge capacities of 386 and $253 \mathrm{mAh} \mathrm{g}^{-1}$, excellent rate-performances and excellent cycle stabilities (84.5\%, 2000 cycles; $85.0 \%, 500$ cycles). More importantly, the combination of the surface-dominated redox reactions of iodine with the intrinsic intercalative properties of such a porous graphitic carbon in a full metallic $\mathrm{Li} / \mathrm{Na}$-electrode-free batteries led to high reversible capacities of up to $217 / 182 \mathrm{mAh} \mathrm{g}^{-1}$ for iodine-carbon full batteries with a $\mathrm{Li}$-/Na-ion electrolyte, respectively, and good cycling stabilities (76.7\%@500 cycles and 69.8\%@300 cycles at a current density of $500 \mathrm{~mA} \mathrm{~g}^{-1}$ ). The methodology developed in this study opens new avenues for the development of novel rechargeable batteries, even free from the metallic $\mathrm{Li} / \mathrm{Na}$ anode and associated safety risk, from low-cost heteroatom-doped porous graphitic carbon via the combination of redox capacitive properties and ion intercalation.

\section{Methods}

Preparation of heteroatom doped porous carbon matrix. $1.2 \mathrm{ml}$ aniline monomer was added into $30 \mathrm{ml}$ phytic acid solution. $1.0 \mathrm{~g}$ of ammonium persulfate (APS) was dissolved into the $15 \mathrm{~mL}$ deionized (DI) water under stirring. After cooling down to about $4{ }^{\circ} \mathrm{C}$, both solutions were mixed together. Cellulose wiper was immersed into above solution and kept at $4^{\circ} \mathrm{C}$ for overnight. The resultant wiper was washed with a large amount of DI water and dried at $60^{\circ} \mathrm{C}$, followed by annealing at $1000^{\circ} \mathrm{C}$ for $2 \mathrm{~h}$ in $\mathrm{N}_{2}$. In order to prepare nitrogen doped carbon cloth (NCC), the as-prepared wiper was washed with $10 \%$ ammonia water (de-doping process) to remove phytic acid before thermal treatment. For comparison, polyaniline aerogel were also prepared by the same procedure and carbonized at $1000^{\circ}$ $\mathrm{C}$ for $2 \mathrm{~h}$ in $\mathrm{N}_{2}$. Pure carbon cloth was obtained by directly pyrolysis of cellulose cloth under same experimental condition.

The loading of iodine on various carbon scaffolds. Iodine was loaded on various carbon scaffolds according to a simple inside encapsulation method. Typically, $10 \mathrm{mg}$ of iodine was added into $20 \mathrm{ml}$ DI water. Notably, most of iodine particles remain undissolved at the bottom due to the low solubility. HPMC-NP and other carbon materials were immersed into the above solution for a certain time, respectively. During the inside encapsulation process, it can be seen that most of iodine particles disappeared gradually. Then, the obtained sample was dried at $80^{\circ} \mathrm{C}$. The iodine adsorbed on carbon scaffolds was measured according to the mass change before and after the encapsulation process. The mass loading of iodine was normalized to the total mass of iodine and carbon unless otherwise stated. Notably, the mass ratio in Fig. 2a was based on the mass of carbon.

Structural characterization. The phase purity and crystal structure of the products were determined by XRD measurements. XPS was recorded on an ESCALAB $250 \mathrm{X}$-ray photoelectron spectrometer. The Raman spectra were collected on LabRAM HR 800 system using $514 \mathrm{~nm}$ laser. SEM images were measured on a Hitachi $\times 650$ electron microscope. TEM images were presented on a JEOL JEM2100 microscope. The thermostability of iodine-carbon composite was determined by Thermogravimetric analysis (TGA). The heating rate is $5^{\circ} \mathrm{C} \mathrm{min}^{-1}$ from roomtemperature to $400{ }^{\circ} \mathrm{C}$ under $\mathrm{N}_{2}$. Brunauere-Emmete-Teller (BET) isotherms and specific surface area (i.e., BET surface area) were measure with a Kubo $\times 1000$ instrument at $77 \mathrm{~K}$. Prior to subsequent measurements, the $\mathrm{I}_{2}$-loaded porous materials were firstly dried at $80^{\circ} \mathrm{C}$ for $10 \mathrm{~h}$ to remove the surface adsorbed iodine and water. Then, the samples were degassed at $95^{\circ} \mathrm{C}$ for $6 \mathrm{~h}$. The specific surface areas were calculated by the BET method. Pore size distribution curves were computed from the desorption branches of the isotherms using the Barrett, Joyner, and Halenda (BJH) method.

Electrochemical measurements. The Li-/Na-iodine batteries (half-cell) were assembled in an argon-filled glove box. $1 \mathrm{M} \mathrm{LiTFSI}$ in DOL/DME (1:1 by volume) with $1 \mathrm{wt} \% \mathrm{LiNO}_{3}$ and $1 \mathrm{M} \mathrm{NaClO}_{4}$ in EC/DEC (1:1 by volume) were used as the electrolytes, respectively, for $\mathrm{Li}$ - and $\mathrm{Na}$-iodine battery test. Cyclic voltammetry (CV) was performed on a CHI 760e electrochemical workstation. The charge and discharge curves were recorded on a Land CT2001A battery test system. Prior to full-battery fabrication, the anode and cathode were electrochemically activated in a half cell, this step is critical to circumvent the large irreversible capacity and the low Coulombic efficiency (CE).

Computational methods. Density functional theory (DFT) and molecular dynamics (MD) calculations were performed using the Vienna ab initio simulation package $^{51}$. The core-valence interaction was described by the projector augmentedwave (PAW) method ${ }^{52}$. The generalized gradient approximation of Perdew-BurkeErnzerhof (GGA-PBE) ${ }^{53}$ was used to account for the exchange-correlation functional. The plane-wave energy cutoff was set to $400 \mathrm{eV}$. The Monkhorst-Pack scheme ${ }^{54}$ was used to sample the Brillouin zone (BZ). For the single layer, a grid of
$21 \times 21 \times 1$ was used. The van der Waals $(\mathrm{vdW})$ corrections were used in the calculations of the iodine molecules $\left(\mathrm{I}_{2} / \mathrm{LiI}_{3}\right)$ adsorption for the systems of pure graphene and graphene doped with $\mathrm{N}$ and $\mathrm{P}$. A vacuum region of $20 \AA$ was employed for all the systems to avoid interaction of periodic images. The force convergence criterion was set to $0.01 \mathrm{eV} \AA^{-1}$ for optimization.

Data availability. The relevant data are available within the article and its Supplementary Information file or from the corresponding authors on reasonable request.

Received: 22 February 2017 Accepted: 17 July 2017 Published online: 13 September 2017

\section{References}

1. Tarascon, J.-M. \& Armand, M. Issues and challenges facing rechargeable lithium batteries. Nature 414, 359-367 (2001).

2. Thackeray, M. M., David, W. I. F., Bruce, P. G. \& Goodenough, J. B. Lithium insertion into manganese spinels. Mater. Res. Bull 18, 461-472 (1983).

3. Alper, J. The battery: not yet a terminal case. Science 296, 1224-1226 (2002).

4. Ji, X., Lee, K. T. \& Nazar, L. F. A highly ordered nanostructured carbon-sulphur cathode for lithium-sulphur batteries. Nat. Mater. 8, 500-506 (2009).

5. Raccichini, R., Varzi, A., Passerini, S. \& Scrosati, B. The role of graphene for electrochemical energy storage. Nat. Mater. 14, 271-279 (2015).

6. Karthik, M., Faik, A., Doppiu, S., Roddatis, V. \& D’Aguanno, B. A simple approach for fabrication of interconnected graphitized macroporous carbon foam with uniform mesopore walls by using hydrothermal method. Carbon 87, 434-443 (2015).

7. Jung, S.-K. et al. Lithium-free transition metal monoxides for positive electrodes in lithium-ion batteries. Nat. Energy 2, 16208 (2017).

8. Su, D., McDonagh, A., Qiao, S. Z. \& Wang, G. High-capacity aqueous potassium-ion batteries for large-scale energy storage. Adv. Mater. 29, 1604007 (2017).

9. Zhou, L. et al. Intricate hollow structures: controlled synthesis and applications in energy storage and conversion. Adv. Mater. 29, 1602914 (2017).

10. Bruce, P. G. Energy storage beyond the horizon: Rechargeable lithium batteries. Solid State Ion 179, 752-760 (2008).

11. Goodenough, J. B. \& Kim, Y. Challenges for rechargeable Li batteries. Chem. Mater. 22, 587-603 (2010).

12. Lee, H. W. et al. Manganese hexacyanomanganate open framework as a highcapacity positive electrode material for sodium-ion batteries. Nat. Commun. 5, 5280 (2014).

13. $\mathrm{Xu}$, J. et al. High-performance sodium ion batteries based on a $3 \mathrm{D}$ anode from nitrogen-doped graphene foams. Adv. Mater. 27, 2042-2048 (2015).

14. Wang, Y. L., Sun, Q. L., Zhao, Q. Q., Cao, J. S. \& Ye, S. H. Rechargeable lithium/ iodine battery with superior high-rate capability by using iodine-carbon composite as cathode. Energy Environ. Sci. 4, 3947-3950 (2011).

15. Zhao, Q., Lu, Y., Zhu, Z., Tao, Z. \& Chen, J. Rechargeable lithium-iodine batteries with iodine/nanoporous carbon cathode. Nano Lett. 15, 5982-5987 (2015).

16. Gong, D. et al. An iodine quantum dots based rechargeable sodium-iodine battery. Adv. Energy Mater. 7, 1601885 (2017).

17. Zhao, Y., Wang, L. \& Byon, H. R. High-performance rechargeable lithiumiodine batteries using triiodide/iodide redox couples in an aqueous cathode. Nat. Commun. 4, 1896 (2013).

18. Zhao, Y. et al. A $3.5 \mathrm{~V}$ lithium-iodine hybrid redox battery with vertically aligned carbon nanotube current collector. Nano. Lett. 14, 1085-1092 (2014).

19. Su, Z. et al. Ultra-small $\mathrm{B}_{2} \mathrm{O}_{3}$ nanocrystals grown in situ on highly porous carbon microtubes for lithium-iodine and lithium-sulfur batteries. J. Mater. Chem. A 4, 8541-8547 (2016).

20. Xin, S. et al. Smaller sulfur molecules promise better lithium-sulfur batteries. J. Am. Chem. Soc. 134, 18510-18513 (2012).

21. Hou, T.-Z. et al. Design principles for heteroatom-doped nanocarbon to achieve strong anchoring of polysulfides for lithium-sulfur batteries. Small $\mathbf{1 2}$ 3283-3291 (2016).

22. $\mathrm{Ma}$, Q. et al. Carbon-based functional materials derived from waste for water remediation and energy storage. Adv. Mater. 29, 1605361 (2017).

23. Wang, Y.-X. et al. Achieving high-performance room-temperature sodiumsulfur batteries with S@interconnected mesoporous carbon hollow nanospheres. J. Am. Chem. Soc. 138, 16576-16579 (2016)

24. Liang, H.-W., Zhuang, X., Brüller, S., Feng, X. \& Müllen, K. Hierarchically porous carbons with optimized nitrogen doping as highly active electrocatalysts for oxygen reduction. Nat. Commun. 5, 4973 (2014). 
25. Zhang, J., Zhao, Z., Xia, Z. \& Dai, L. A metal-free bifunctional electrocatalyst for oxygen reduction and oxygen evolution reactions. Nat. Nanotechnol. 10, 444-452 (2015).

26. Zhang, C., Mahmood, N., Yin, H., Liu, F. \& Hou, Y. Synthesis of phosphorusdoped graphene and its multifunctional applications for oxygen reduction reaction and lithium ion batteries. Adv. Mater. 25, 4932-4937 (2013).

27. Yu, Z. L. et al. Ion-catalyzed synthesis of microporous hard carbon embedded with expanded nanographite for enhanced lithium/sodium storage. J. Am. Chem. Soc. 138, 14915-14922 (2016).

28. Jiang, Y. et al. Prussian blue@C composite as an ultrahigh-rate and long-life sodium-ion battery cathode. Adv. Funct. Mater. 26, 5315-5321 (2016).

29. Sun, Y. M. et al. High-capacity battery cathode prelithiation to offset initial lithium loss. Nat. Energy 1, 15008 (2016).

30. Wang, H. et al. A high-energy lithium-ion capacitor by integration of a 3D interconnected titanium carbide nanoparticle chain anode with a pyridinederived porous nitrogen-doped carbon cathode. Adv. Funct. Mater. 26, 3082-3093 (2016).

31. Varzi, A., Bresser, D., Zsmory, J. V., Müller, F. \& Passerini, S. $\mathrm{ZnFe}_{2} \mathrm{O}_{4}-\mathrm{C} /$ $\mathrm{LiFePO}_{4}$-CNT: a novel high-power lithium-ion battery with excellent cycling performance. Adv. Energy Mater. 4, 1400054 (2014).

32. Ding, J. et al. Exceptional energy and new insight with a sodium-selenium battery based on a carbon nanosheet cathode and a pseudographite anode. Energy Environ. Sci. 10, 153-165 (2017).

33. Liu, Q. S., Zheng, T., Wang, P., Jiang, I. P. \& Li, N. Adsorption isotherm, kinetic and mechanism studies of some substituted phenols on activated carbon fibers. Chem. Eng. J. 157, 348-356 (2010).

34. Li, Z., Tao, J., Cheng, Y. M., Li, J. \& Lou, X. W. Pie-like electrode design for high-energy density lithium-sulfur batteries. Nat. Commun. 6, 8850 (2015).

35. Zhang, H., Yu, F., Kang, W. \& Shen, Q. Encapsulating selenium into macro-/micro-porous biochar-based framework for high-performance lithium-selenium batteries. Carbon 95, 354-363 (2015).

36. Su, Y. S. \& Manthiram, A. Lithium-sulphur batteries with a microporous carbon paper as a bifunctional interlayer. Nat. Commun. 3, 1166 (2012).

37. Lu, K., Xu, J., Zhang, J., Song, B. \& Ma, H. General preparation of threedimensional porous metal oxide foams coated with nitrogen-doped carbon for enhanced lithium storage. ACS Appl. Mater. Interfaces 8, 17402-17408 (2016).

38. Wang, S. et al. Vertically aligned BCN nanotubes as efficient metal-free electrocatalysts for the oxygen reduction reaction: a synergetic effect by co-doping with boron and nitrogen. Angew. Chem. Int. Ed. 50, 11756-11760 (2011).

39. Zhao, M. Q. et al. Unstacked double-layer templated graphene for high-rate lithium-sulphur batteries. Nat. Commun. 5, 3410 (2014).

40. Sun, T. et al. A biodegradable polydopamine-derived electrode material for high-capacity and long-life lithium-ion and sodium-ion batteries. Angew. Chem. Int. Ed. 55, 10662-10666 (2016).

41. Jiao, Y., Zheng, Y., Davey, K. \& Qiao, S.-Z. Activity origin and catalyst design principles for electrocatalytic hydrogen evolution on heteroatom-doped graphene. Nat. Energy 1, 16130 (2016).

42. Chaudhari, N. K., Song, M. Y. \& Yu, J.-S. Heteroatom-doped highly porous carbon from human urine. Sci. Rep. 4, 5221 (2014).

43. Zhou, G. et al. Catalytic oxidation of $\mathrm{Li}_{2} \mathrm{~S}$ on the surface of metal sulfides for Li-S batteries. Proc. Natl Acad. Sci. USA 114, 840-845 (2017).

44. Zhang, J. et al. A conductive molecular framework derived $\mathrm{Li}_{2} \mathrm{~S} / \mathrm{N}, \mathrm{P}$-codoped carbon cathode for advanced lithium-sulfur batteries. Adv. Energy Mater. 7, 1602876 (2017)

45. Kovalenko, I. et al. A major constituent of brown algae for use in high-capacity Li-ion batteries. Science 334, 75-79 (2011).

46. Chao, D. et al. Array of nanosheets render ultrafast and high-capacity Na-ion storage by tunable pseudocapacitance. Nat. Commun. 7, 12122 (2016).

47. Sathiya, M., Prakash, A. S., Ramesha, K., Tarascon, J.-M. \& Shukla, A. K. $\mathrm{V}_{2} \mathrm{O}_{5}$-anchored carbon nanotubes for enhanced electrochemical energy storage. J. Am. Chem. Soc. 133, 16291-16299 (2011).

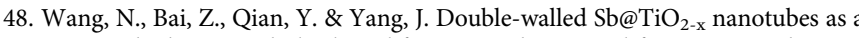
superior high-rate and ultralong-lifespan anode material for Na-ion and Li-ion batteries. Adv. Mater. 28, 4126-4133 (2016).

49. Wu, X., Gao, Y., Ai, X., Qian, J. \& Yang, H. A low-cost and environmentally benign aqueous rechargeable sodium-ion battery based on $\mathrm{NaTi}_{2}\left(\mathrm{PO}_{4}\right)_{3-}$ $\mathrm{Na}_{2} \mathrm{NiFe}(\mathrm{CN})_{6}$ intercalation chemistry. Electrochem. Commun. 31, 145-148 (2013).

50. Kim, J.-H., Kim, J.-S., Lim, Y.-G., Lee, J.-G. \& Kim, Y.-J. Effect of carbon types on the electrochemical properties of negative electrodes for Li-ion capacitors. $J$. Power Sources 196, 10490-10495 (2011).

51. Kresse, G. \& Furthmüller, J. Efficient iterative schemes for ab initio total-energy calculations using a plane-wave basis set. Phys. Rev. B: Condens. Matter Mater Phys. 54, 11169-11186 (1996).

52. Blöchl, P. E. Projector augmented-wave method. Phys. Rev. B: Condens. Matter Mater. Phys. 50, 17953-17979 (1994).

53. Perdew, J. P., Burke, K. \& Ernzerhof, M. Generalized gradient approximation made simple. Phys. Rev. Lett. 77, 3865-3868 (1996).

54. Monkhorst, H. J. \& Pack, J. D. Special points for Brillouin-zone integrations. Phys. Rev. B: Solid State 13, 5188-5192 (1976).

\section{Acknowledgements}

This work was financially supported by the Natural Scientific Foundation of China (Nos 21503116 and 21673130), Distinguished Scientist Program at BUCT (buctylkxj02), Key Program of National Natural Science Foundation of China, and The National Key Research and Development Program of China (2017YFA0206500). The Taishan Scholars Program of Shandong Province (No. tsqn20161004) and the Youth 1000 Talent Program of China are also acknowledged.

\section{Author contributions}

K.L. and J.Z. conceived and designed the experiments. K.L. performed sample characterization and electrochemical studies. Z.H. performed the density functional theory calculations. K.L., J.Z., J.M., H.M. and L.D. analyzed the experimental data and wrote the paper. All authors discussed the results and commented on the manuscript.

\section{Additional information}

Supplementary Information accompanies this paper at doi:10.1038/s41467-017-00649-7.

Competing interests: The authors declare no competing financial interests.

Reprints and permission information is available online at http://npg.nature.com/ reprintsandpermissions/

Publisher's note: Springer Nature remains neutral with regard to jurisdictional claims in published maps and institutional affiliations.

Open Access This article is licensed under a Creative Commons Attribution 4.0 International License, which permits use, sharing, adaptation, distribution and reproduction in any medium or format, as long as you give appropriate credit to the original author(s) and the source, provide a link to the Creative Commons license, and indicate if changes were made. The images or other third party material in this article are included in the article's Creative Commons license, unless indicated otherwise in a credit line to the material. If material is not included in the article's Creative Commons license and your intended use is not permitted by statutory regulation or exceeds the permitted use, you will need to obtain permission directly from the copyright holder. To view a copy of this license, visit http://creativecommons.org/ licenses/by/4.0/.

(c) The Author(s) 2017 